\title{
Sense and sense-forming technologies in teaching foreign languages
}

\author{
Olga Godovanaya \\ Southern Federal University, Institute of Philology, Journalism and Intercultural Communication, \\ 344006 Rostov-on-Don, Russian Federation.
}

\begin{abstract}
In the modern educational setting, there is a trend towards the transition to digital learning, but many psychologists and educators believe that this process will lead to a simple absorption of information and the degradation of education system as a whole. This article deals with the importance of bringing knowledge to the personal semantic level, it also considers the mechanisms of generating sense and highlights the techniques that facilitate the initiation of semantic value in the context of teaching foreign languages.
\end{abstract}

In the modern educational setting, there is a tendency for switching to digital learning. Despite the relevance of this transformation, such a process seems impossible to many leading scientists in the field of pedagogy and psychology. In fact, it deprives the educational process of the most important humanistic component. In the framework of this approach, a student is considered to be "... a kind of mechanical device contrary to the anthropological ideas of K.D. Ushinsky, P.F. Kapterev, and other classics of Russian pedagogy" [1]. A.A. Verbitsky argues that "... information and knowledge are different entities: information is an objectively existing sign system (meaning) while knowledge is something subjective, a personality substructure, having personal meaning (sense)." [1]

Knowledge that is not endowed with personal meanings does not represent value for a person. Sense is an integrative basis of personality and lies at the basis of motivational drive for an action. D.A. Leontiev, B.S. Bratus, A.G. Asmolov, and others wrote about this in their works. We turn to the definition of sense given by D.A. Leontiev. He characterizes the semantic level of personality as "... a layer of semantic structures in which a certain substantial relationship of a person with the world is crystallized and which regulate his life" [2].

The semantic structures (sense, semantic attitudes, motives, etc.) provide the semantic regulation of specific actions and a human life as a whole.

As for the importance of personal meaning in teaching, A.N. Leontiev wrote that knowledge filled with personal meanings "activates the consciousness, self-knowledge, and self-understanding of a person and it naturally leads him to mental enrichment and comprehensive development". The motive enriched with personal senses becomes internal [3].

Sense becomes a structural component of a personality in the course of time. D.A. Leontiev identifies the following psychological mechanisms of semantic generation: 
closure of life relationships, induction of meaning, identification, insight, clash of meanings, positioning of meanings [2].

Knowledge of the mechanisms of semantic generation is necessary for a teacher to manage classes properly and to know which pedagogical methods can bring learning to the personal-semantic level. We will try to extrapolate the listed mechanisms onto the field of studying foreign languages.

The closure of life relations is understood as the acquisition of new personal meaning because of the subject's interaction with an object or a phenomenon. In the context of studying foreign languages, in a situation of real communication, a student faces the necessity to interact in English, so communicative motivation and knowledge of a foreign language acquire a new meaning for him.

Semantic induction is the process of imparting new meanings to activities that were initially devoid of any valuable significance for the subject. When a teacher is methodically wise at managing his classes, creating friendly and working atmosphere in the classroom, and at the same time he uses didactic materials with sense-initiating potential, the student's attitude toward learning a foreign language changes.

Identification of oneself with a particular social group forces a person to "appropriate" semantic orientations of this group. For example, when a student with a low language level starts studying in an advanced group, he begins to appropriate the values of his classmates and, thus, seeks to keep up with the colleagues.

Insight is "a sudden comprehension of a meaning where there was none before" [2]. So, when solving a problem situation in an English class, a student suddenly realizes that he needs to speak the foreign language to solve the specific problem.

Semantic clash occurs during the interaction between subjects or between a subject and an object, a different meanings holder. The clash may result in the subject's self-reflection, change or a complete rejection of personal senses. Provided the interaction in a foreign language classroom is organised correctly (pair work, group work, task-based learning), a semantic clash will occur. Thus, collective interaction has a powerful sense-initiating potential. Collective forms of learning underlie the pedagogical systems of A.S. Makarenko, Sh.A. Amonashvili, D. B. Elkonin, and V.V. Davydov. They provide a high "density of communication" (I.A. Zimnaya) and maximum involvement of students.

Semantic assumption is ".. a special existential act in which a subject makes a decision to attach significance to something in his life" [2]. To use the potential of this method of semantic initiation it is important to pursue discussions concerning the need for studying a foreign language; to conduct a survey in order to provide students with the opportunity to reflect on this topic, evaluate their knowledge, and set tasks to achieve a certain language level by the end of the course being studied. It is important to bring knowledge to a personal-semantic level, so that there is an understanding that the study of the foreign language is necessary [4].

To influence the semantic sphere of students, namely, the processes of semantic dynamics "in which and through which any changes in the semantic sphere occur" semantic techniques are used in the educational process. According to D.A. Leontiev, a semantic technique is a variety of a psychotechnique [2].

Let us single out some semantic techniques used in teaching foreign languages.

1. The emotional and psychological impact.

Interaction in foreign language classes can occur according to the patterns: teacherstudent, teacher-group, student-student, and student-group. However, whatever the form of communication is, the subjects of the interaction exert direct or indirect influence on one another, and an exchange of personal meanings takes place in the course of communication.

The following forms of emotional-psychological impact are distinguished: catching, suggestion and imitation, persuasion [4]. The first three forms relate to suggestive impact, 
while the latter is rational and turns to logic. A.A. Leontiev identifies two main ways of persuasion. The first one is the announcement of new information about a known subject. The second one is the direct impact on the semantic field of the recipient "in order to change his attitude to the surrounding reality, without affecting his abstract knowledge of it" [2]. In the process of suggestive influence, the transmission of personal meanings occurs indirectly.

Catching is understood as "the effect of multiple amplification of the emotional states of the people involved in the communication". Emotions do not make sense but "fulfil the auxiliary function of presenting a personal meaning at a conscious level, not only reflecting it but attracting attention to it and putting the task of revealing it" [2].

As for suggestion and imitation, these forms of influence were particularly emphasized by the Bulgarian psychotherapist Georgi Lozanov back in the 1960s. He developed a unique method of suggestive influence on students, which later became known as "suggestgestopedia" (from lat. Suggestio meaning suggestion, hint + Greek. Paideia meaning training) that is the use of suggestion methods in learning. The essence of this method was to remove complexes and barriers in people learning a foreign language and further, introducing them into a state of physical relaxation and mental focus, to achieve the effect of hypermnesia (i.e., over-memorization).

According to G. Lozanov, suggestive means of influence include:

- Unconditional authority of the teacher that contributes to an unconscious increase in susceptibility to information.

- Infantilization, the students' state of complete trust and weakened criticality in the classroom. One of the means to achieve this condition is role-playing.

- Duplicity (the use of gestures, facial expressions, intonation, rhythm, a special manner of speaking), through which an impact is exerted on the right lobe of the brain being little involved in traditional training.

- Concert pseudo-passivity, a condition that occurs in students at the stage of presenting new material and causes hypomnesia, i.e. over-memorization, accompanied by a state of rest. G. Lozanov experimentally proved that hypomnesia does not occur in a state of muscle relaxation, hypnosis or even sleep, but in a state of calm confidence in the suggestive program as it happens during a concert [6].

In suggestive pedagogy, the attention of students switches from memorization (of information units) and skills formation to proficiency and communication.

2. Sense-bearing context.

According to the principles of contextual education by A.A. Verbitsky, a student perceives not ready-made information about the "foundations of science", but only what he receives in the course of "his own, internally motivated activity aimed at objects and phenomena of the surrounding world and himself" [1]. A.A. Verbitsky identifies the following basic principles of contextual learning:

- student's personal involvement in educational activities;

- modelling the forms of professional activity in the classroom setting;

- problem-based learning;

- the leading role of joint activities;

- vocational training parallel to professional education, etc.

All these principles relate to teaching students in universities regardless of the discipline being studied. The principles can be successfully applied in foreign language classrooms as well.

3. Game technology.

Game technologies occupy a special position in the methodology of teaching foreign languages since they have powerful sense-initiating potential. A.N. Leontiev, L.S. 
Vygotsky, P.Ya. Galperin, L.V. Zaporozhets, F. Buytendijk, J. Kollarits., J. Piaget, etc. made a huge contribution to the research of the game.

A game has always been an integral part of socialization throughout the history of human development. A game is "a kind of reconstruction of a human activity with social, in fact, human essence, with tasks and norms of relations between people" [7]. The main goal of a game is to reproduce social relations between people. According to P.Ya. Galperin, a game is an intermediate stage in mental activities formation [7]. Moreover, many researchers also agree that a game is entertaining in nature and is a powerful tool for relieving tension (F. Schiller, G. Spencer).

Given the listed functions of the game, one should not underestimate the role of game technologies in teaching foreign languages. In a teaching context, game technologies are understood as didactic games, their purpose is to imitate a social situation in which it becomes necessary to use certain speech skills.

A game situation generates a need for communication and brings the latter to the level of personal meaning, that contributes to imprinting, a memorization mechanism of the "once and forever" type, which is possible only in a state of "perceived tension" and "speech need". Then a "trap" for the word is formed in memory, and, as a result, the word is imprinted [8].

According to D.B. Elkonin, the main item of the game is a role. Thanks to the role, a participant in a role-based communication can both "express himself" and "get hidden" (A. A. Leontiev), while having self-control and tension weakened. "In the framework of the game activity, which becomes plausible when its motive and purpose coincide, the personality traits of each participant, the hidden and sometimes unrealized features of his character and temperament manifest themselves much more easily" [9]. Role assignments are formulated in such a way as to initiate personal interest and motivation of the student to solve the given problem. In foreign language classes, the following forms of role-play communication are used: round table discussion, group discussion, panel discussion, dramatization, brainstorming, case studies, etc.

We have examined the importance of personal meaning and sense-forming technologies in an educational context. The educational process, which has a sense-forming potential, brings students' knowledge to a new level, changing their semantic attitudes and helping them overcome many psychological barriers in the study of foreign languages.

\section{References}

1. A.A. Verbitsky, Anthr. Kn. As Syst. Form. Fact. Of Profes. Ped. Ed. Int. Sc.-Pr. Conf. Col. 26-29, (2019)

2. D.A. Leontiev, Psychology of sense: nature, structure and dynamics of semantic reality 2nd, rev. ed. (Smysl, Moscow, 2003)

3. I.V. Abakumova, Learning and sense: meaning formation in the educational process. (Psychological and didactic approach) (Rostov University, Rostov-on-Don, 2003)

4. O.N. Godovanaya, New Par. of Inn. Sc. Form. and Dev. in Mod. Soc., 186-188, (2018)

5. T.I. Guseva. Psychology of Personality. Lecture notes (Phoenix, Rostov-on-Don, 2004)

6. O.N. Godovanaya, Innov. Pot. Of Ed. Env. Subj. in Mod. Soc., 248-256, (2014)

7. D.B. Elkonin. Game pychology. 2nd ed. (Vlados, Moscow, 1999)

8. A.A. Leontiev. Psychological foundations of teaching a non-native language. An anthology (Modek, Moscow, 2004)

9. G.A. Kitaygorodskaya. Intensive teaching of foreign languages. Theory and practice: guidance manual. 2nd ed. (Scientific and Educational Center "Kitaigorodskaya School", Moscow, 2009) 